\title{
Adaptación del Inventario de Perspectiva Temporal Futura de Zimbardo en estudiantes universitarios de Buenos Aires
}

\section{Adaptation of the Future Temporary Perspective Inventory of} Zimbardo in university students of Buenos Aires

Recepción del artículo: 23-01-2020 | Aceptación del artículo: 04-06-2020

Paula Grasso Imig

Facultad de Psicología y Relaciones

Humanas. Universidad Abierta

Interamericana (Argentina) paula.grasso@uai.edu.ar

https://orcid.org/0000-0003-1977-6805
Para referenciar este artículo:

Grasso, P. (2020). Adaptación del Inventario de Perspectiva Temporal Futura de Zimbardo en estudiantes universitarios de Buenos Aires.

Revista ConCiencia EPG, 5(1), 53-84. https://doi.org/10.32654/CONCIENCIAEPG.5-1.5

\section{Resumen}

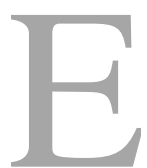

l objetivo de este trabajo fue analizar las propiedades psicométricas del Inventario de Perspectiva Temporal de Zimbardo, en estudiantes universitarios de Buenos Aires. Participaron 334 sujetos (68.6\% mujeres, $31.4 \%$ hombres; Medad $=25.90$, DEedad $=8.23$ ), a quienes se les administró un protocolo integrado por una encuesta sociodemográfica y otra de datos académicos, el Inventario de Perspectiva Temporal de Zimbardo (Zimbardo \& Boyd, 1999) y el Big Five Inventory - versión local adaptada por Castro Solano y Casullo (2001)-. A partir de un análisis de componentes principales, con rotación Varimax, se obtuvo una estructura compuesta de 35 ítems, distribuidos en siete dimensiones $(\mathrm{KMO}=.800$; Bartlett: X2= 3459.355; 595 gl), que explicaron el $52.85 \%$ de la varianza total. Se encontró evidencia de validez concurrente en los análisis de correlación con las dimensiones de personalidad; para la consistencia interna se calcularon alfas de Cronbach que resultaron adecuados para cada uno de los factores, y estos resultados se corroboraron con el cálculo de alfas ordinales (dadas las características de los ítems), que arrojaron valores similares. También, en lo referido a la consistencia interna, se realizó una división por mitades, con la fórmula Sperman - Brown, y el resultado da cuenta de una relación 
estadísticamente significativa $(\mathrm{p}<.05)$, con un coeficiente de correlación fuerte $(\mathrm{p}=$ $.000 ; \rho=.946)$. Además, se analizó la estabilidad temporal y los resultados mostraron valores que sostienen dicha estabilidad. En función de estos resultados se cuenta con un inventario que dispone de las propiedades psicométricas esperadas, para ser utilizado en sujetos de características semejantes.

Palabras clave: perspectiva temporal, validez de constructo, consistencia interna, estabilidad temporal.

\section{Abstract}

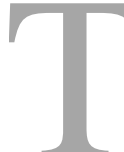

he objective of this work was to analyze the psychometric properties of the Zimbardo Temporary Perspective Inventory, in university students of Buenos Aires. 334 subjects participated $(68.6 \%$ women, $31.4 \%$ men; Medad $=25.90$, DEedad $=8.23$ ), who were administered a protocol composed of a sociodemographic survey and another academic data, the Zimbardo Temporary Perspective Inventory (Zimbardo \& Boyd, 1999) and the Big Five Inventory - local version adapted by Castro Solano and Casullo (2001) -. From a principal component analysis, with Varimax rotation, a structure composed of 35 items was obtained, distributed in seven dimensions $(\mathrm{KMO}=.800$; Bartlett: $\mathrm{X} 2=$ 3459.355; 595 gl), which explains 52.85\% of the variance total. Evidence of concurrent validity was found in the correlation analysis with personality dimensions; For internal consistency, Cronbach alphas were calculated that were specific for each of the factors, and these results were corroborated with the calculation of ordinal alphas (given the characteristics of the items), which yielded similar values. Also, in terms of internal consistency, a division was made by halves, with the Sperman-Brown formula, and the result of the account of a statistically significant relationship ( $p<.05)$, with a strong correlation coefficient $(\mathrm{p}=.000 ; \rho=$ .946). In addition, the temporal stability and the results affected values that sustain said stability were analyzed. Based on these results, there is an inventory that has the expected psychometric properties, to be used in subjects with similar characteristics.

Key words: temporal perspective, construct validity, internal consistency, temporal stability.

\section{Resumo}

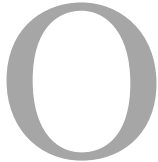

objetivo deste trabalho foi analisar as propriedades psicométricas do Inventário de Perspectiva Temporária de Zimbardo, em estudantes universitários de Buenos Aires. Participaram 334 sujeitos (68,6\% mulheres, 31,4\% homens; Medad= 25,90, DEedad= 8,23), aos quais foi administrado um protocolo composto por uma pesquisa sociodemográfica e outros dados acadêmicos, o Inventário de Perspectiva Temporária de Zimbardo (Zimbardo \& Boyd, 1999) e o Big Five 
Inventory - versão local adaptada por Castro Solano e Casullo (2001) -. A partir de uma análise de componentes principais, com rotação Varimax, foi obtida uma estrutura composta por 35 itens, distribuídos em sete dimensões (KMO = .800; Bartlett: X2 = 3459.355; 595 gl), o que explica $52,85 \%$ da variância total. Evidências de validade concorrente foram encontradas na análise de correlação com as dimensões da personalidade; Para consistência interna, foram calculados os alfas de Cronbach, específicos para cada um dos fatores, e esses resultados foram corroborados com o cálculo dos alfas ordinais (dadas as características dos itens), que apresentaram valores semelhantes. Além disso, em termos de consistência interna, foi feita uma divisão por metades, com a fórmula de SpermanBrown, e o resultado da conta de uma relação estatisticamente significante (p $<0,05)$, com forte coeficiente de correlação ( $\mathrm{p}=0,000 ; \rho=0,946)$. Além disso, a estabilidade temporal e os resultados afetaram os valores que sustentam a referida estabilidade. Com base nesses resultados, existe um inventário com as propriedades psicométricas esperadas, para ser utilizado em indivíduos com características semelhantes.

Palavras-chave: perspectiva temporal, validade de construto, consistência interna, estabilidade temporal.

Palavras-chave: perspectiva temporal, validade de construto, consistência interna, estabilidade temporal.

\section{Introducción}

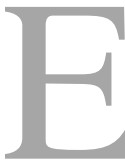

l estudio del tiempo es un tema que ha interesado a buena parte de la investigación, siendo varias las disciplinas muy interesadas en él, así como la Psicología, desde hace algunos años. Tal es así, que se ha transformado en una parte relevante de la cognición humana y de cómo influye en la conciencia (Díaz Morales, 2006a, 2006b).

La Perspectiva Temporal se define como la representación mental que las personas tienen acerca de diferentes acontecimientos (Zimbardo \& Boyd, 1999). D’Alessio, Guarino, De Pascalis y Zimbardo (2003) la describieron como un proceso fundacional en el desempeño del sujeto, tanto del individuo como de éste en sociedad. Este proceso es no consciente, y las categorías temporales involucradas cumplen un rol central en la relación que hay entre las experiencias de carácter personal y las de carácter social, lo que a su vez permite dar orden, coherencia y sentido a la vida del sujeto, ya sea en el pasado, presente o un posible futuro (D'Alessio et al., 2003; Sircova et al., 2014, 2015; Stolarski, Matthews, Postek, Zimbardo \& Bitner, 2013). Dicho de otra forma, se ha llegado a determinar que el tiempo le da sentido a las experiencias vividas, a la vez que permite autorregular el comportamiento presente y anticipar el futuro (Díaz Moralez, 2006a, 2006b; González Lomelí, Maytorena, Lohr Escalante \& Carreño Cruz, 2006). 


\section{Perspectiva temporal futura}

Específicamente, en lo que refiere a la Perspectiva Temporal Futura (en adelante PTF), pueden observarse varias definiciones. Originalmente, Bleger (1963) la describió como la acción recíproca que explica la manera en que experiencias del pasado se asocian a la forma como las personas viven el presente, y en cómo esto repercute en la proyección del futuro. Asimismo, explica que el futuro condiciona la forma en que se vive el presente y la valoración respecto del pasado, de la propia historia. En adición, Lewin (1942) explica que es el grado y la forma en que el futuro cronológico se integra en el espacio de la vida del individuo.

En Europa, la conceptualización de la PTF tiene una larga tradición en la Psicología, y es así que se observan varios autores que han esbozado diferentes ideas acerca de esto. Lersch (1966) expresa que tanto pasado como futuro se encuentran contenidos en la vivencia presente; de esa manera, todo presente es a la vez un adelanto del futuro. Esta apreciación articula la vida anímica del sujeto con la orientación en la que éste se encuentre, y lo dispone a la realización de un estado que aún no existe. Para Fraisse (1963), el futuro tendrá lugar siempre que éste se perciba como posible de ser realizado; este futuro es movido por un deseo previo. De esta forma, para este autor la idea se resume en la necesidad de un deseo por algo y en la conciencia de que puede ser logrado, ambos aspectos deben estar presentes para que haya futuro.
En una línea parecida, Nuttin (1964) indica una asociación entre el futuro y la motivación, es decir, que no solamente lo va a entender como una consecuencia y aprendizaje de los eventos pasados, sino que le va a dar al futuro una cualidad de meta-objeto. De esta manera, el futuro se transforma en un espacio motivacional de primera categoría. No obstante, esta cualidad se limita a una orientación general, a un futuro inmediato, debido a que su impulso es la necesidad. Entiende que la perspectiva temporal es la representación mental que los seres humanos realizan acerca de diferentes acontecimientos, haciendo referencia tanto al pasado como al futuro, pero es la elaboración de proyectos la que da origen a la orientación futura (Nuttin, 1985).

Por su parte, Nurmi (1991) caracteriza la PTF como un proceso biológico complejo, que se constituye a partir de las expectativas que las personas tienen de sí mismas en el futuro y el grado en que se reflexiona acerca de ello. La PTF se encuentra asociada al contexto social y cultural del sujeto, así como también a la etapa del desarrollo en que se ubica. De forma parecida, Husman y Lens (1999) expresan que se trata del grado y la manera en la cual el futuro cronológico es integrado en el espacio vital presente del individuo, a través de procesos motivacionales de establecimiento de metas. Y ya de forma más integrada, Zimbardo y Boyd (1999), asocian la PTF a la capacidad de entender las consecuencias de los actos a realizar, a tener objetivos claros, poder tolerar tanto el placer como las tensiones que puedan aparecer a partir del proceso de llevar a cabo las metas propuestas. 
Teniendo en cuenta lo explicado, puede decirse que la PTF es entendida como las creencias o la orientación de un sujeto en torno al futuro, a partir de diferentes objetivos que son distantes temporalmente; de manera usual se la asocia a una representación que está relacionada con diferentes aspectos de la vida. En ese sentido es posible entenderla como una actitud en relación a un objetivo específico, en un tiempo determinado.

\section{Modelo de Perspectiva Temporal de Zimbardo e Inventario}

Para Zimbardo y Boyd (1999) la PTF debe ser entendida en términos de orientación temporal, lo que implica reconocer la tendencia que el sujeto tiene de estar centrado en el pasado, en el presente o el futuro, es decir se trata de la prevalencia de una de éstas sobre las otras. Es un proceso que se encuentra en el origen del comportamiento, que permite organizar la conducta en diferentes momentos, dando sentido y coherencia a la experiencia, lo que al mismo tiempo brinda orden tanto a los sucesos como a la vida misma. A pesar de no ser tangible del todo, se trata de un proceso que tiene lugar en las personas, y que permite organizar tanto las experiencias de carácter individual como social.

A pesar de todo esto, Zimbardo y Boyd (1999) resaltan que, en la mayoría de los casos, se trata de un proceso no consciente, es decir que aun cuando quedan adscriptas las experiencias más personales o sociales en alguno de estos marcos o categorías temporales, las personas no siempre saben que lo están haciendo o proveen de intensión a la acción.
Para Vázquez et al. (2016) es importante hacer notar el peso relativo que cada uno de estos marcos temporales adquiera para el sujeto, ya que esto establece diferencias importantes respecto de las decisiones y comportamientos que se tienen; por esto resulta importante analizar las modalidades que cada una de estas categorías temporales adquiera en cada quien. Respecto de las preferencias por alguna de las dimensiones temporales, Zimbardo, Keough y Boyd (1997) señalaron que las mismas pudieran funcionar como un rasgo estático de la personalidad, lo que también tiene algunos costos, y que para Boniwell (2009) en ocasiones pudieran ser desadaptativos.

Respecto de las formas de posicionarse en el tiempo, Zimbardo y Boyd (1999, 2008) describen diferentes dimensiones para la PTF; se trata de cinco formas en las cuales se le da sentido al tiempo, se lo valora, y que se conforman en base a las tres categorías importantes ya conocidas: pasado, presente y futuro. Galarraga (2016) explica que esto permite dar cuenta de la forma en que las personas se refieren al propio tiempo. Las cinco dimensiones propuestas por Zimbardo y Boyd (1999) son las siguientes:

- Pasado positivo: se asocia a las experiencias que tuvieron las personas y que recuerdan como agradables y placenteras.

- Pasado negativo: refiere a los sucesos que tienen carga negativa, ya que resultaron difíciles $y$ complicados. 
- Presente hedonista: tiene que ver con la búsqueda de sensaciones que producen placer en el marco de las situaciones que se viven de forma diaria.

- Presente fatalista: se relaciona con las experiencias actuales de las personas, pero que generan ansiedad y miedo.

- Futuro: se encuentra referido a planifica las acciones en función de los objetivos que se establecieron para alcanzar determinadas metas.

La dinámica de estas categorías muestra que quienes tienen una orientación temporal enmarcada hacia el presente están más pendientes de lo percibido en un determinado momento; entre las características observadas puede notarse que son de pensamientos concretos, y que -en general- no se los nota interesados en acontecimientos pasados o venideros, así como tampoco están al pendiente de las consecuencias de sus actos. En cambio, quienes presentan una orientación hacia el pasado si bien tampoco demuestran interés en los sucesos del futuro, sí mantienen una conducta más estable a lo largo del tiempo, y se enfocan en los compromisos que asumen, siendo estos de la índole que sea (académica, familiar, laboral). Para quienes muestran una orientación hacia el futuro dan cuenta de un interés asociado a esta orientación temporal, así como de las consecuencias de dichos actos; en general poseen objetivos claros, lo que les ayuda a mantener el equilibrio entre el placer, la tolerancia y las tensiones entre las distintas situaciones que se produzcan al momento de querer llevar a cabo las metas que se proponen (Galarraga, 2016; Zimbardo \& Boyd, 1999).

Para resumir lo explicado sobre este modelo, puede decirse que los autores entienden que la perspectiva temporal es un proceso que se encuentra en la génesis del comportamiento humano, tanto a nivel individual como social; se trata de un proceso no consciente, pero que igualmente permite realizar análisis, así como también organizar, el continuo devenir de la conducta en distintos marcos temporales, y esto permite que los comportamientos se doten de sentido y coherencia (Brenlla et al., 2017; Zimbardo \& Boyd, 1999). Los marcos temporales, en los cuales las personas ubican sus experiencias, representan justamente la forma en la que se dividen las experiencias en cuanto al devenir de la propia existencia, aunque se esto se realice de manera automática y no consciente. En esta concepción del concepto se supone una articulación balanceada entre las distintas instancias temporales, lo que lleva al sujeto a tener flexibilidad y armonía conductual cuando debe enfrentar demandas situacionales, y cuando se trata del logro de una competencia temporal para lograr una mejor adaptación (Brenlla et al., 2017; Zimbardo \& Boyd, 1999; Zaleski, 1994). Los autores consideran la idea de que la perspectiva temporal conforma un estilo disposicional relativamente estable, y por este motivo es también considerada como rasgo de la personalidad (Boniwell \& Zimbardo, 2004; Boyd \& Zimbardo, 2005; Brenlla et al., 2017; Vázquez et al., 2016; Zimbardo et al., 1997; Zimbardo, 2002; Zimbardo \& Boyd, 1999). 
En la Tabla 1 se presenta un resumen del modelo y los factores que

Tabla 1

Desarrollos relevantes sobre la PTF incluye el modelo de Zimbardo y Boyd (1999)

\begin{tabular}{|c|c|c|c|}
\hline Autor / es & Año & Definición & Dimensiones \\
\hline $\begin{array}{c}\text { Zimbardo \& } \\
\text { Boyd }\end{array}$ & 1999 & $\begin{array}{l}\text { Es un proceso que se encuentra en } \\
\text { la génesis del comportamiento } \\
\text { humano, tanto a nivel individual } \\
\text { como social; es no consciente, pero } \\
\text { que igualmente permite realizar } \\
\text { análisis, así como también } \\
\text { organizar, el continuo devenir de la } \\
\text { conducta en distintos marcos } \\
\text { temporales }\end{array}$ & $\begin{array}{l}\text { - Pasado positivo } \\
\text { - Pasado negativo } \\
\text { - Presente } \\
\text { - } \text { Hedonista } \\
\text { - } \text { Presente fatalista }\end{array}$ \\
\hline
\end{tabular}

Basados en sus desarrollos, Zimbardo y Boyd (1999) diseñaron un instrumento para evaluar la PTF, el Inventario de Perspectiva Temporal de Zimbardo. A partir de trabajar con una muestra compuesta por estudiantes universitarios, y de realizar análisis de componentes principales, con rotación Varimax, pudieron operacionalizar su modelo, obteniendo una estructura que permite evaluar las cinco dimensiones propuestas, a partir de 56 ítems, que además explica el $36 \%$ de la varianza. Además, verificaron estos resultados con análisis factoriales confirmatorios.

Luego de su desarrollo, se han validado diversas adaptaciones de este inventario, hechas en distintos contextos, que mostraron estructura similar, así como pequeñas variaciones respecto de la cantidad de ítems. Algunos ejemplos son en Francia, hecho por Apostolidis y Fieulaine
(2004), España, realizada por Díaz Morales (2006), en Brasil por Leite y Pascuali (2008), por un lado, y por Milfont, Andrade, Belo y Pessoa (2008), por otro; también en Portugal fue adaptada por Ortuño y Gamboa (2009) y en Lituania por Liniauskaite y Kairys, en 2009. Luego en Grecia la adaptación la realizaron Anagnostopoulos y Griva (2011), en Japón Shimojima, Sato y Ochi (2012) y en Chile fue realizada por Oyanadel, Buela Casal y Pérez-Fortis (2014). Hubo otros desarrollos que también obtuvieron como resultado cinco factores, pero a partir de versiones que reducían la cantidad de ítems, como son los casos de Estonia (Seema \& Sircova, 2013), Israel (Orikini, 2014) y Republica Checa (Kostal, Klicperová-Baker, Lukavská \& Lukavsky, 2015). Incluso, un estudio realizado en colaboración entre 24 países obtuvo resultados similares a los de la escala original (Sirvoca et al. 2014). 
Por otra parte, en algunos de los estudios se ha obtenido una factorización menor, como son los casos de la versión realizada por D'Alessio et al. (2003) en Italia, que obtuvieron como resultado final tres factores (futuro, presente hedonista y fatalista), y la versión de México, en la cual también se obtuvieron tres dimensiones, solo que en este caso se trató de pasado, presente y futuro (Corral Verdugo, Fraijo Sing \& Pinheiro, 2006). Por último, hubo estudios que han añadido escalas, como el desarrollado por Carelli, Wiber y Wiber (2011) en Suecia, en el cual se tuvo en cuenta el futuro negativo, y el desarrollado en República Checa por Kostal et al. (2015), en el que se trabajó también con futuro positivo.

A continuación, se presenta la Tabla 2 , tomada de lo desarrollado por Galarraga (2016), para mostrar los detalles de las versiones especificadas hasta aquí.

Tabla 2

Estudios factoriales PTF de Zimbardo y Boyd (Galarraga, 2016)

\begin{tabular}{|c|c|c|c|c|c|c|c|c|}
\hline \multirow{2}{*}{ Autor / es } & \multirow{2}{*}{ Año } & \multirow{2}{*}{ País } & \multirow{2}{*}{ Participantes } & \multirow{2}{*}{ Ítems } & \multicolumn{2}{|r|}{ Factores } & \multirow{2}{*}{ Análisis } & \multirow{2}{*}{ \% V. E. $[1]$} \\
\hline & & & & & № & Nombre & & \\
\hline Zimbardo \& Boyd & 1999 & EE.UU & $\begin{array}{c}1034 \\
\text { estudiantes } \\
\text { universitarios. }\end{array}$ & 56 & 5 & $\begin{array}{l}\text { Pasado negativo } \\
\text { Presente } \\
\text { hedonista } \\
\text { Futuro } \\
\text { Pasado positivo } \\
\text { Presente } \\
\text { fatalista }\end{array}$ & $\begin{array}{c}\text { ACP } \\
\text { (Varimax) } \\
\text { AFC }\end{array}$ & 36 \\
\hline $\begin{array}{l}\text { D'Alessio, } \\
\text { Guarino, De } \\
\text { Pascalis \& } \\
\text { Zimbardo }\end{array}$ & 2003 & Italia & 1507 adultos. & 22 & 3 & $\begin{array}{c}\text { Futuro } \\
\text { Presente } \\
\text { hedonista } \\
\text { Presente } \\
\text { fatalista }\end{array}$ & $\begin{array}{c}\text { AFE } \\
\text { (Varimax) }\end{array}$ & 30.08 \\
\hline \multirow{2}{*}{$\begin{array}{l}\text { Apostolidis \& } \\
\text { Fieulaine }\end{array}$} & \multirow{2}{*}{2004} & \multirow{2}{*}{ Francia } & \multirow{2}{*}{$\begin{array}{l}419 \text { estudiantes } \\
\text { universitarios }\end{array}$} & 56 & 5 & $\begin{array}{c}\text { Igual a } \\
\text { Zimbardo y Boyd } \\
\text { (1999) }\end{array}$ & $\begin{array}{c}\text { ACP } \\
\text { (Varimax) }\end{array}$ & 32.75 \\
\hline & & & & 54 & 5 & $\begin{array}{c}\text { Igual a } \\
\text { Zimbardo y Boyd } \\
\text { (1999) }\end{array}$ & $\mathrm{AFC}$ & - \\
\hline $\begin{array}{l}\text { Corral Verdugo, } \\
\text { Fraijo Sing \& } \\
\text { Pinheiro }\end{array}$ & 2006 & México & 300 adultos & 56 & 3 & $\begin{array}{l}\text { Pasado } \\
\text { Presente } \\
\text { Futuro }\end{array}$ & $\mathrm{AFC}$ & - \\
\hline
\end{tabular}




\begin{tabular}{|c|c|c|c|c|c|c|c|c|}
\hline Díaz Morales & 2006 & España & 756 adultos & 56 & 5 & $\begin{array}{c}\text { Igual a } \\
\text { Zimbardo y Boyd } \\
\text { (1999) }\end{array}$ & $\begin{array}{c}\text { ACP } \\
\text { (Varimax) }\end{array}$ & 33.82 \\
\hline $\begin{array}{l}\text { Milfont, Andrade, } \\
\text { Belo \& Pessoa }\end{array}$ & 2008 & Brasil & $\begin{array}{c}247 \text { estudiantes } \\
\text { universitarios }\end{array}$ & 38 & 5 & $\begin{array}{c}\text { Igual a } \\
\text { Zimbardo y Boyd } \\
\text { (1999) }\end{array}$ & $\mathrm{AFC}$ & - \\
\hline \multirow[t]{2}{*}{ Leite \& Pascuali } & \multirow[t]{2}{*}{2008} & \multirow[t]{2}{*}{ Brasil } & $\begin{array}{c}528 \text { estudiantes } \\
\text { universitarios }\end{array}$ & 56 & 5 & \multirow{2}{*}{$\begin{array}{c}\text { Igual a } \\
\text { Zimbardo y Boyd } \\
\text { (1999) }\end{array}$} & \multirow[t]{2}{*}{$\begin{array}{c}\text { ACP } \\
\text { (Varimax) }\end{array}$} & 33.38 \\
\hline & & & 1047 adultos & 58 & 5 & & & 31.91 \\
\hline Ortuño \& Gamboa & 2009 & Portugal & 277 adultos & 56 & 5 & $\begin{array}{c}\text { Igual a } \\
\text { Zimbardo y Boyd } \\
\text { (1999) }\end{array}$ & $\begin{array}{c}\text { AFE } \\
\text { (Varimax) }\end{array}$ & 35.25 \\
\hline \multirow{2}{*}{$\begin{array}{c}\text { Liniauskaite \& } \\
\text { Kairys }\end{array}$} & \multirow[t]{2}{*}{2009} & \multirow[t]{2}{*}{ Lituania } & 619 adultos & \multirow[t]{2}{*}{56} & \multirow[t]{2}{*}{5} & \multirow{2}{*}{$\begin{array}{c}\text { Igual a } \\
\text { Zimbardo y Boyd } \\
\text { (1999) }\end{array}$} & $\begin{array}{c}\text { AFE } \\
\text { (Varimax) }\end{array}$ & 34.7 \\
\hline & & & 625 adultos & & & & $\mathrm{AFC}$ & - \\
\hline $\begin{array}{l}\text { Anagnostopoulos } \\
\text { \& Griva }\end{array}$ & 2011 & Grecia & $\begin{array}{l}337 \text { estudiantes } \\
\text { universitarios }\end{array}$ & 56 & 5 & $\begin{array}{c}\text { Igual a } \\
\text { Zimbardo y Boyd } \\
\text { (1999) }\end{array}$ & $\begin{array}{c}\text { ACP } \\
\text { (Varimax) } \\
\text { AFC }\end{array}$ & 33.2 \\
\hline $\begin{array}{c}\text { Carelli, Wiberg \& } \\
\text { Wiberg }\end{array}$ & 2011 & Suecia & 419 adultos & 64 & 6 & $\begin{array}{c}\text { Pasado negativo } \\
\text { Presente } \\
\text { hedonista } \\
\text { Futuro } \\
\text { Pasado positivo } \\
\text { Presente } \\
\text { fatalista } \\
\text { Futuro negativo }\end{array}$ & $\mathrm{AFC}$ & - \\
\hline $\begin{array}{c}\text { Shimojima, Sato } \\
\text { \& Ochi }\end{array}$ & 2012 & Japón & $\begin{array}{l}748 \text { estudiantes } \\
\text { universitarios }\end{array}$ & 56 & 5 & $\begin{array}{c}\text { Igual a } \\
\text { Zimbardo y Boyd } \\
\text { (1999) }\end{array}$ & $\begin{array}{c}\text { AFE } \\
\text { (Promax) } \\
\text { AFC } \\
\end{array}$ & 37 \\
\hline Brenlla et al. & 2013 & Argentina & 430 adultos & 56 & 5 & $\begin{array}{c}\text { Igual a } \\
\text { Zimbardo y Boyd } \\
\text { (1999) }\end{array}$ & AFE & - \\
\hline Seema \& Sircova & 2013 & Estonia & $\begin{array}{c}447 \text { estudiantes } \\
\text { universitarios }\end{array}$ & 25 & 5 & $\begin{array}{c}\text { Igual a } \\
\text { Zimbardo y Boyd } \\
\text { (1999) }\end{array}$ & AFE AFC & - \\
\hline Orkibi & 2014 & Israel & $\begin{array}{c}572 \text { estudiantes } \\
\text { de nivel medio y } \\
\text { universitarios }\end{array}$ & 20 & 5 & $\begin{array}{c}\text { Igual a } \\
\text { Zimbardo y Boyd } \\
\text { (1999) }\end{array}$ & $\mathrm{AFC}$ & - \\
\hline $\begin{array}{c}\text { Oyanadel, Buela } \\
\text { Casal \& Pérez } \\
\text { Fortis }\end{array}$ & 2014 & Chile & 604 adultos & 56 & 5 & $\begin{array}{c}\text { Igual a } \\
\text { Zimbardo y Boyd } \\
\text { (1999) }\end{array}$ & $\begin{array}{c}\text { ACP } \\
\text { (Varimax) }\end{array}$ & 33 \\
\hline
\end{tabular}




\begin{tabular}{|c|c|c|c|c|c|c|c|c|}
\hline \multirow[t]{2}{*}{$\begin{array}{c}\text { Kostal, } \\
\text { Klicperová Baker } \\
\text { Lukavská \& } \\
\text { Lukavsky }\end{array}$} & \multirow[t]{2}{*}{2015} & \multirow[t]{2}{*}{$\begin{array}{c}\text { República } \\
\text { Checa }\end{array}$} & \multirow[t]{2}{*}{$\begin{array}{c}1032 \text { adultos } \\
\text { checos y } \\
1036 \text { adultos } \\
\text { eslovacos }\end{array}$} & 18 & 6 & $\begin{array}{c}\text { Pasado negativo } \\
\text { Presente } \\
\text { hedonista } \\
\text { Futuro } \\
\text { Pasado positivo } \\
\text { Presente } \\
\text { fatalista } \\
\text { Futuro positivo }\end{array}$ & AFC & - \\
\hline & & & & 15 & 5 & $\begin{array}{c}\text { Igual a } \\
\text { Zimbardo y Boyd } \\
\text { (1999) }\end{array}$ & AFC & - \\
\hline
\end{tabular}

[1] V.E.: Varianza explicada.

\section{Perspectiva temporal en el ámbito de la educación superior}

Diversos estudios han retomado la PTF en el ámbito de la Educación Superior, dado que se trata de una variable que se encuentra asociada a diferentes aspectos de la vida en los estudiantes de este tramo. En términos generales, se ha observado que puede combinarse con la teoría de la meta, en el área de la motivación y el logro, dado que los patrones más adaptativos y positivos aparecen cuando los individuos cuentan con valores intrínsecos, que les permiten plantearse metas a futuro y así determinar los pasos para llevarlas a cabo, esto -a su vez- mantiene un patrón motivacional respecto de la tareas futuras y refuerza las conductas orientadas al éxito (Lens \& Dora, 2005; Simons, Dewitte \& Lens, 2001). Herrera, Matos, Martínez y Lens (2015) describieron la asociación entre PTF y satisfacción con la vida en estudiantes universitarios, encontrando que la representación subjetiva del futuro afecta de manera considerable las conductas y desempeño de las metas y proyectos. En ese sentido, si la representación es positiva la satisfacción es mayor y las conductas orientadas al logro de las metas son proactivas; de forma contraria, si dicha representación es de carácter negativo, la satisfacción es menor y las conductas hacia la concreción de metas no resultan del todo efectivas. En la misma línea, Difabio de Anglat, Vázquez y Noriega Biggio (2018) analizaron la relación entre la orientación temporal y calidad de metas vitales, y pudieron dar cuenta que las metas vitales más adaptativas se asocian a las categorías temporales positivas, mientras que con las metas menos adaptativas sucede lo contrario, lo que estaría asociado también al ámbito académico. De la misma manera, existen otros estudios que describen los efectos, directos e indirectos, entre morosidad en las tareas académicas, propensión hacia el futuro y desempeño académico en estudiantes del ámbito superior, a partir de los cuales se pudo indicar que la mayor morosidad se asocia a las dimensiones más negativas de la perspectiva temporal, como presente fatalista $\mathrm{y}$ pasado negativo. Al mismo tiempo, esto permite entender y reforzar la asociación de estos resultados con los niveles de deserción en el nivel superior, hecho que se condice con lo que también 
sucede en los niveles que le preceden (González Lomelí et al., 2006). En suma, Gutiérrez Braojoz, Salmerón Pérez y Muñoz Cateros (2014) observaron que si el logro académico se obtiene a partir del aprendizaje autorregulado es porque el sujeto tiene un patrón temporal proactivo; el resto de los patrones se asocian al aprendizaje regulado externamente. Los autores sugieren que el factor temporal es el que explica el cambio cualitativo, que permite a los estudiantes pasar de un aprendizaje regulado externamente a uno autorregulado.

En virtud de lo antedicho y teniendo en cuenta la creciente demanda y aumento de matrícula observadas en el nivel superior, tanto como los resultados obtenidos en diversas investigaciones en esta área, comienza a plantearse en qué formas puede optimizarse la calidad en lo que refiere al aprendizaje, así como de las variables que intervienen en él. En suma, cuando se observa la situación de la educación en el nivel universitario local puede entenderse que la misma no es la esperada, obteniendo como resultado altos porcentajes de deserción y bajos desempeños académicos (Fernández Lamarra, 2009; García de Fanelli, 2014; Goldenhersh, Coria \& Saino, 2011; Soria \& Dalfaro, 2012). Es por eso que desarrollar las herramientas que permitan dar cuanta de cuáles son los factores que estarían interviniendo en este sentido se torna una tarea relevante. En ese sentido, la perspectiva temporal muestra evidencia de su importancia en esta instancia en la vida de las personas, dado que su orientación condiciona determinadas conductas que resultan funcionales. Retomando esta idea, el objetivo de este trabajo es analizar las propiedades psicométricas del Inventario de Perspectiva Temporal de Zimbardo, a partir de realizar la adaptación lingüística, conceptual y métrica, para su uso en estudiantes del ámbito superior de la Provincia de Buenos Aires.

\section{Método}

Participantes. Participaron 334 estudiantes universitarios, de diferentes carreras y pertenecientes a establecimientos de gestión privada, de la Provincia de Buenos Aires (68.6\% mujeres, $31.4 \%$ hombres), con edades comprendidas entre los 18 y 55 años $\left(\mathrm{M}_{\text {edad }}=25.90, \mathrm{DE}_{\text {edad }}=\right.$ 8.23). En cuanto a la carrera elegida la mayoría de los participantes estudia en la Lic. en Psicología (20,1\%), luego el 14,7\% Lic. en Diseños Gráfico y el 14,1\% Medicina; el resto de las carreras arrojó una distribución más pareja; lo propio sucedió en lo referido a la distribución según facultad (se muestra en la Tabla 3).

Para el grupo de convivencia, la mayor parte de los encuestados reportó que vivía con la familia de origen $(66,8 \%)$, siguiéndole quienes lo hacen con familia propia con un $21,9 \%$, y luego, en un menor porcentaje, se encuentran quienes viven solos o con amigos, reportando el 8,1\% de los casos, y, por último, quienes indicaron otro tipo de convivencia (3,3\%). Luego, en cuanto al estado civil, la mayor parte de la muestra indicó que son solteros, siendo el $88,3 \%$ de la muestra; el resto de las categorías alcanzaron porcentajes muy bajos. En lo que respecta a la situación laboral la mayoría de los participantes 
señaló que trabaja (Sí= 61.1\% y No= $38.9 \%)$.

Tabla 3

Resumen de frecuencias para Facultades y Carreras.

\begin{tabular}{|c|c|c|c|c|c|}
\hline \multicolumn{3}{|l|}{ Facultad } & \multicolumn{3}{|l|}{ Carrera } \\
\hline & $n$ & $\%$ & & $n$ & $\%$ \\
\hline Psicología y Relaciones Humanč & 67 & 20.1 & Lic. en Psicología & 67 & 20.1 \\
\hline \multirow{2}{*}{ Medicina y Ciencias de la Salud } & \multirow{2}{*}{83} & \multirow{2}{*}{24.9} & Medicina & 48 & 14.1 \\
\hline & & & Lic. en Prod. Bioimág. & 35 & 10.5 \\
\hline \multirow{3}{*}{ Comunicación y Ciencias Social } & \multirow{3}{*}{112} & \multirow{3}{*}{33.5} & Lic. en Diseño Gráfico & 49 & 14.7 \\
\hline & & & Lic. en Relac. Públicas & 32 & 9.6 \\
\hline & & & Lic. en Prod. y Realiz. Audiv. & 31 & 9.3 \\
\hline Tecnología Informática & 39 & 11.7 & Ing. en Sistemas Informáticos & 39 & 11.7 \\
\hline Derecho y Ciencias Políticas & 33 & 9.9 & Abogacía & 33 & 9.9 \\
\hline
\end{tabular}

\section{Materiales}

- Encuesta de datos sociodemográficos y académicos. Para recolectar información acerca de edad, sexo, estado civil, situación laboral, grupo de convivencia, nivel socioeconómico percibido, $\mathrm{y}$ también sobre la cantidad de veces que recursa alguna asignatura, la cantidad de veces que ha quedado libre (tanto por abandono como por inasistencia), la veces que ha desaprobado, la cantidad de asignaturas que lleva aprobadas, las que ha desaprobado, cuántas asignaturas prevé su carrera.

- Inventario de Perspectiva Temporal de Zimbardo (Zimbardo \& Boyd, 1999). Evalúa las preferencias y creencias, así como los valores que se le asignan a cada una de las instancias temporales. Está conformado por 56 ítems, que se responden en base a una escala de tipo Likert de 5 categorías, y se distribuyen en 5 dimensiones: pasado negativo, pasado positivo, presente hedonista, presente fatalista y futuro.

- Big Five Inventory (adaptación al medio local de Castro Solano \& Casullo, 2001). Evalúa los cinco grandes factores de la personalidad (Neuroticismo, Extraversión, Agradabilidad, Apertura a la experiencia y Responsabilidad) a partir de la distribución de 44 ítems; las opciones de respuesta toman el formato de una escala tipo Likert, con cinco opciones de respuesta, que van desde Muy en desacuerdo a Muy de acuerdo.

Procedimiento. Se efectuaron administraciones individuales y grupales dependiendo de la cantidad de sujetos que hubiera habido en el momento-. La 
participación fue voluntaria, informándose mediante consentimiento informado que los datos derivados de esta investigación se serían utilizados con fines exclusivamente científicos, bajo la Ley Nacional 25.326 de protección de los datos personales.

Para la validación del Inventario de Perspectiva Temporal de Zimbardo (Zimbardo \& Boyd, 1999), se realizó la traducción de los reactivos a partir de la colaboración de tres expertos en el idioma inglés, sobre la cual luego se trascribió el inventario y se agregaron 9 reactivos, dado que se esperaba una factorización más amplia (de 7 dimensiones); luego se realizó una prueba piloto a 30 sujetos. Posteriormente, se realizó el juicio experto, con la participación de 5 jueces. En función de esto se realizaron modificaciones a los reactivos y se obtuvo la versión preliminar. Una vez que se contó con dicha versión -en los momentos que los estudiantes quedaban libres de las clases que estaban tomando-, se administraron las encuestas sociodemográfica y académica, el Inventario de Perspectiva Temporal de Zimbardo (Zimbardo \& Boyd, 1999) y el Big Five Inventory (Castro Solano \& Casullo, 2001). En cuanto al análisis de los datos, se determinó la dimensionalidad del instrumento mediante estudios factoriales exploratorios (Hair, Anderson, Tatham \& Black, 1999), aportándose evidencias de validez de constructo. Esto se realizó con análisis de rotación ortogonal Varimax, ya que fue utilizada originalmente, y si bien se han realizado modificaciones respecto de la primera versión, se mantiene este tipo de rotación debido a la tendencia de este procedimiento a asimilar cada variable a un eje, lo que facilita la interpretación de los componentes (Martínez Arias, 1999; Tabachnick \& Fidell, 2001). Luego se retiraron aquellos ítems que puntuaban bajo $(<.40)$ en las comunalidades (Martínez Arias, 1999) y se repitió el procedimiento sin ellos. La confiabilidad se determinó a partir de análisis de consistencia interna de cada factor, por medio del cálculo de los coeficientes Alpha de Cronbach y ordinal (coeficiente Omega) y con división por mitades; además se analizó la estabilidad temporal a partir de una nueva toma de datos, realizada a los tres meses a 30 estudiantes, para el análisis test / re-test con pruebas $t$ para muestras relacionadas.

\section{Resultados}

En primera instancia, se corroboró la dimensionalidad de la escala. Es importante resaltar que, si bien se trata de la adaptación de un inventario preexistente, también se realizan sobre el mismo modificaciones en cuanto a la cantidad de ítems y la dimensionalidad propuesta, dado que existen estudios previos que mostraron una solución factorial más amplia (e.g. Carelli et al., 2011; Kostal et al., 2015), y se espera que esto aporte a una descripción más minuciosa acerca de la experiencia académica. Por lo tanto, se verificaron la solución factorial, la matriz antiimagen y las comunalidades, el índice de esfericidad y la varianza explicada. Se realizó con rotación ortogonal Varimax.

En cuanto al primer análisis factorial se obtuvo como resultado un KMO elevado, que muestra un nivel adecuado de ajuste, que se corrobora con un nivel de significación inferior al $p$ valor estipulado de $.05(\mathrm{KMO}=.787-p=$ $.000)$. Respecto de la matriz anti - imagen se 
evidencia que las correlaciones entre los ítems son altas, con una tendencia importante hacia el 1. No obstante, aparecen en las comunalidades varios ítems con valores inferiores a .40. En esta línea, cuando se analiza la matriz de estructura se evidencia que ítem 10 no pesa en alguna de las dimensiones del instrumento.

Una vez obtenidos estos resultados se repitió el procedimiento, pero esta vez extrayendo los ítemes que obtuvieron valores menores a .40 en las comunalidades, y el ítem 10 (que no tuvo peso para alguna de las dimensiones en la matriz de estructura). En esta oportunidad todos los valores aumentaron. Puede observarse que el índice de esfericidad es más elevado $(\mathrm{KMO}=.800, p=.000)$ (Tabla 4), al igual que las comunalidades, mostrando una adecuación apropiada, es decir mayor a .40 (Tabla 5); en lo que refiere a la matriz anti-imagen, los valores se mantuvieron fuertes (Tabla 5)

Tabla 4

KMO y prueba esfericidad de Barlett (final)

\begin{tabular}{lr}
\hline Medida de adecuación muestral de Kaiser-Meyer-Olkin. (Índice KMO) & .800 \\
Chi-cuadrado & 3459.355 \\
Prueba de esfericidad de Barlett - $p$ valor & .000 \\
\hline
\end{tabular}

Tabla 5

Matriz de correlación anti-imagen y comunalidades (final)

\section{Correlación \\ Comunalidades \\ anti-imagen}

\section{Ítems}

$r$

Extracción

2. las imágenes, sonidos y olores de la infancia a menudo traen lindos recuerdos.

5. Antes de realizar cualquier actividad es importante organizar todo de manera minuciosa y luego seguir.

6. Mis decisiones son mayormente influenciadas por la gente que me rodea.

7. Creo que el día de una persona debe ser planeado con anticipación cada mañana. 
8. Me gusta pensar en el pasado.

.653

.579

11. Cuando quiero lograr algo, establezco metas y considero medios específicos para alcanzarlas.

13. En balance, hay mucho más bueno que malo para recordar en mi pasado.

16. Cumplir con los plazos de trabajos para mañana es más importante que la diversión de esta noche.

.732

17. Puesto que lo que sea será, realmente no importa lo que yo haga.

19. Las dolorosas experiencias pasadas se repiten en mi mente.

20. Trato de vivir mi vida al máximo en cada detalle.

23. Recuerdos felices de los buenos tiempos salen fácilmente a la mente.

24. Me gusta saber con bastante anticipación cada paso a seguir cuando acepto alguna actividad.

30. El pasado tiene demasiados recuerdos desagradables en los cuales prefiero no pensar.

31. Es importante poner emoción en mi vida.

32. Buscar nuevas metas me hace sentir que puedo conocer mejor mis expectativas futuras.

33. He cometido errores en el pasado que me gustaría poder deshacer.

37. Tomar riesgos evita que mi vida se vuelva aburrida.

38. Para mi es más importante disfrutar de la vida en el momento en lugar de concentrarse en lo que sucederá.

39. Me da tranquilidad poder usar en el futuro lo que aprendí de errores pasados.

41. Es difícil para mí olvidar las imágenes desagradables de mi juventud.

43. La vida es un regalo y hay que aprender a vivir con lo que venga.

44. Incluso cuando estoy pasándola bien en el presente suelo hacer comparaciones con experiencias similares pasadas. 
45. Uno no puede planificar el futuro porque las cosas cambian mucho.

46. Mi vida está determinada por fuerzas en las que no puedo influir.

47. No tiene sentido preocuparse por el futuro, ya que no hay nada que yo pueda hacer al respecto.

48. Completo los proyectos a tiempo haciendo un progreso constante.

50. Tomo riesgos para ponerle emoción a mi vida.

51. Hago listas de cosas para hacer.

54. Soy capaz de resistirme a las tentaciones cuando sé que hay trabajo por hacer.

55. Me dejo llevar por el momento.

.690

56. La vida de hoy es muy complicada; preferiría la vida más sencilla del pasado.

59. Pienso en las cosas malas que me han pasado en el pasado.

62. En general es más importante tener suerte que trabajar duro.

En lo referido a la varianza explicada (Tabla 6), los resultados obtenidos permiten observar que explica el 52,85 \% de la varianza, y para cada una de las dimensiones -al igual que antes- puede notarse que la diferencia porcentual entre cada factor es bastante parecida, aunque no son parejas. Por último, en cuanto a la matriz de correlaciones se puede observar que la asociación entre los factores es fuerte (Tabla 7) 
Tabla 6

Varianza explicada (final)

\begin{tabular}{ccc}
\hline \multicolumn{3}{c}{ Varianza explicada } \\
\hline Factor & \% & \% acumulado \\
\hline $\mathbf{1}$ & 12.209 & 12.209 \\
$\mathbf{2}$ & 7.615 & 19.824 \\
$\mathbf{3}$ & 7.078 & 26.902 \\
$\mathbf{4}$ & 6.977 & 33.879 \\
$\mathbf{5}$ & 6.682 & 40.560 \\
$\mathbf{6}$ & 6.422 & 46.982 \\
$\mathbf{7}$ & 5.869 & 52.851 \\
\hline
\end{tabular}

Tabla 7

Matriz de correlaciones de componentes de rotación

\begin{tabular}{llllllll}
\hline Componente & $\mathbf{1}$ & $\mathbf{2}$ & $\mathbf{3}$ & $\mathbf{4}$ & $\mathbf{5}$ & $\mathbf{6}$ & $\mathbf{7}$ \\
\hline $\mathbf{1}$ & .836 & -.009 & .401 & -.222 & .067 & .053 & .289 \\
$\mathbf{2}$ & .011 & .725 & .167 & .323 & .239 & .514 & -.141 \\
$\mathbf{3}$ & .213 & -.096 & -.342 & .572 & .587 & -.329 & .221 \\
$\mathbf{4}$ & -.479 & .040 & .519 & -.270 & .505 & -.177 & .375 \\
$\mathbf{5}$ & -.053 & .516 & -.255 & -.021 & -.416 & -.259 & .652 \\
$\mathbf{6}$ & .006 & .095 & .560 & .471 & -.322 & -.534 & -.258 \\
$\mathbf{7}$ & -.153 & -.433 & .215 & .474 & -.251 & .490 & .464 \\
\hline
\end{tabular}

A partir de todos estos procedimientos se obtuvo una escala que cuenta 35 ítems, distribuidos en 7 dimensiones: Pasado Negativo (1), Pasado Positivo (2), Presente Fatalista (3), Futuro Positivo (4), Futuro Neutro (5), Presente Hedonista (6) y Futuro Negativo (7). Se pudo observar que en la mayoría de los casos se distribuyeron como en la escala original. En este caso, se vieron repartidos los ítems de Futuro -de la escala original- en Futuro positivo y Futuro Neutro de esta nueva versión-, y el ítem 13 obtuvo un peso mayor en el factor Pasado Negativo, a diferencia de la escala original, en la que se ubica en Pasado Positivo. Lo mismo sucedió con los ítems 20 y 55, que en la versión original 
formaban parte de la dimensión Presente Hedonista, y en esta nueva escala son parte de Pasado Positivo y Futuro Positivo, respectivamente. A continuación, se presenta la Tabla 8, de componentes rotados, con la versión final del inventario, que muestra la agrupación de ítems para cada factor y sus cargas.

Tabla 8

Matriz de componentes rotados

\begin{tabular}{|c|c|c|c|c|c|c|c|}
\hline \multirow[b]{2}{*}{ Reactivos } & \multicolumn{7}{|c|}{ Componentes } \\
\hline & 1 & 2 & 3 & 4 & 5 & 6 & 7 \\
\hline $\begin{array}{l}\text { 41. Es difícil para mí olvidar las } \\
\text { imágenes desagradables de mi } \\
\text { juventud. }\end{array}$ & .792 & .006 & .126 & -.077 & .041 & .034 & -.043 \\
\hline $\begin{array}{l}\text { 30. El pasado tiene demasiados } \\
\text { recuerdos desagradables en los } \\
\text { cuales prefiero no pensar. }\end{array}$ & .760 & -.013 & .121 & -.058 & .014 & .049 & -.120 \\
\hline $\begin{array}{l}\text { 59. Pienso en las cosas malas } \\
\text { que me han pasado en el pasado. }\end{array}$ & .755 & -.078 & .096 & .044 & -.005 & .006 & .278 \\
\hline $\begin{array}{l}\text { 19. Las dolorosas experiencias } \\
\text { pasadas se repiten en mi mente. }\end{array}$ & .729 & -.084 & .083 & .071 & -.024 & .094 & .321 \\
\hline $\begin{array}{l}\text { 33. He cometido errores en el } \\
\text { pasado que me gustaría poder } \\
\text { deshacer. }\end{array}$ & .638 & -.078 & .096 & .044 & -.005 & .006 & .278 \\
\hline $\begin{array}{l}\text { 63. Pienso en las cosas buenas } \\
\text { que he perdido en mi vida. }\end{array}$ & .610 & -.036 & .240 & -.141 & .110 & .050 & .269 \\
\hline
\end{tabular}

44. Incluso cuando estoy pasándola bien en el presente suelo hacer comparaciones con $\begin{array}{lllllll}.602 & .132 & .109 & .026 & .001 & -.092 & .356\end{array}$ experiencias similares pasadas.

13. En balance, hay mucho más bueno que malo para recordar en mi pasado.

$\begin{array}{lllllll}.555 & .333 & .061 & .165 & .096 & -.095 & .321\end{array}$

23. Recuerdos felices de los buenos tiempos salen

fácilmente a la mente.

$\begin{array}{llllll}.646 & -.002 & -.215 & .243 & -.047 & .074\end{array}$


20. Trato de vivir mi vida al máximo en cada detalle.

$-.04$

39. Me da tranquilidad poder usar en el futuro lo que aprendí

.578

.142

$-.079$

.189

$-.009$

de errores pasados.

2. Las imágenes, sonidos y

olores de la infancia a menud

traen lindos recuerdos.

$\begin{array}{lllllll}-.257 & .523 & .007 & .102 & -.041 & .032 & .230\end{array}$

43. La vida es un regalo y hay que aprender a vivir con lo que venga.

$\begin{array}{lllllll}-.020 & .413 & .331 & .195 & -.175 & .199 & -.169\end{array}$

47. No tiene sentido preocuparse por el futuro, ya que no hay nada que yo pueda .089 $\begin{array}{llllll}-.108 & .769 & .034 & -.032 & .045 & -.056\end{array}$ hacer al respecto.

17. Puesto que lo que sea será, realmente no importa lo que yo haga.

$\begin{array}{lllllll}.109 & .049 & .674 & -.171 & .055 & .054 & .070\end{array}$

46. Mi vida está determinadas por fuerzas en las que no puedo influir.

$\begin{array}{lllllll}.234 & .009 & .615 & .007 & .133 & .003 & .141\end{array}$

45. Uno no puede planificar el futuro porque las cosas cambian mucho.

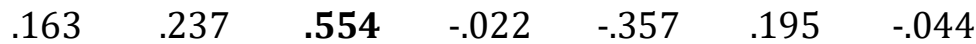

54. Soy capaz de resistirme a las tentaciones cuando sé que hay trabajo por hacer.

$\begin{array}{lllllll}.085 & -.052 & -.029 & .692 & .024 & .041 & .082\end{array}$

16. Cumplir con los plazos de trabajos para mañana es más importante que la diversión de .03 $.079 \quad-.238$ .087 esta noche.

48. Completo los proyectos a tiempo haciendo un progreso constante. 
11. Cuando quiero lograr algo, establezco metas y considero medios específicos para $\begin{array}{llllllll}-.036 & .176 & .005 & .502 & .334 & .017 & -.256\end{array}$ alcanzarlas.

55. Me dejo llevar por el momento.

32. Buscar nuevas metas me hace sentir que puedo conocer mejor mis expectativas futuras.

62. En general es más importante tener suerte que trabajar duro.

.19

$.079 \quad .414$

.423 .198

.049

7. Creo que el día de una persona debe ser planeado con .094 anticipación cada mañana.

5. Antes de realizar cualquier actividad es importante organizar todo de manera

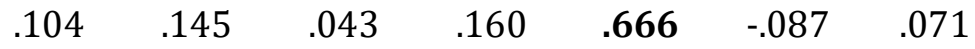
minuciosa y luego seguir.

51. Hago listas de cosas para hacer.

$$
-.08
$$$$
-.181
$$

.051

$-.063$

.639

$.267 \quad-.012$

24. Me gusta saber con bastante anticipación cada paso a seguir cuando acepto alguna actividad.

\begin{tabular}{|c|c|c|c|c|c|c|}
\hline .260 & .372 & .012 & .160 & .550 & -.119 & -.042 \\
\hline
\end{tabular}

37. Tomar riesgos evita que mi vida se vuelva aburrida.

.009

$$
.147
$$

$-.032$

.011

.787

50. Tomo riesgos para ponerle emoción a la vida.

$\begin{array}{lllllll}.014 & .043 & .097 & .018 & .175 & .782 & -.073\end{array}$

31. Es importante poner emoción a mi vida.

$$
.064
$$$$
.448
$$$$
-.076
$$

.140

$-.076$

$.493 \quad-.061$

38. Para mi es más importante disfrutar de la vida en el $-.055$

.338

.248

$-.211$

$-.197$

.469

$-.187$

momento en lugar de 
concentrarse en lo que sucederá.

$\begin{array}{lllllllll}\text { 8. Me gusta pensar en el pasado. } & .216 & .086 & -.082 & .156 & -.041 & -.035 & \mathbf{. 7 0 1}\end{array}$

6. Mis decisiones son mayormente influenciadas por $\begin{array}{llllll}.112 & -.145 & .043 & -.155 & .208 & .007\end{array}$ .621 la gente que me rodea.

56. La vida de hoy es muy complicada; preferiría la vida .197 más sencilla del pasado.

Luego, se analizó la consistencia interna del instrumento, mediante los estadísticos Alpha de Cronbach, por un lado, y con el coeficiente Omega (alfa ordinal), por otro. Para cada una de las dimensiones los resultados obtenidos confirman la consistencia interna de cada una de ellas; en lo que respecta a la dimensión Futuro positivo, si bien el resultado evidencia un valor más bajo en el procedimiento realizado con Alpha de
Cronbach, igualmente se trata de una adecuada consistencia interna para la misma; además, el valor obtenido con el coeficiente Omega es adecuado (目目= .65; o= .72). Al mismo tiempo, Futuro negativo presenta un valor más bajo en el cálculo del alfa ordinal, pero este se encuentra cercano al límite estipulado entre .70 y .90, según los criterios sugeridos por George y Mallery (2003). Estos resultados se presentan en la Tabla 9.

Tabla 9

Consistencia interna para cada dimensión del inventario

\begin{tabular}{lcc}
\hline \multicolumn{3}{c}{ Consistencia interna } \\
\hline \multicolumn{1}{c}{ Dimensiones } & ? de Cronbach & ? ordinal (?) \\
\hline Pasado negativo & .751 & .815 \\
Pasado positivo & .740 & .765 \\
Presente fatalista & .784 & .750 \\
Futuro positivo & .656 & .723 \\
Futuro neutro & .777 & .730 \\
Presente hedonista & .781 & .735 \\
Futuro negativo & .783 & .694 \\
\hline
\end{tabular}


También, en lo referido a la consistencia interna, se realizó una división por mitades, con la fórmula SpermanBrown, y el resultado da cuenta de una relación estadísticamente significativa ( $p<$ $.05)$, con un coeficiente de correlación fuerte $(p=.000 ;$ ? $=.946)$.

Para saber el peso de cada ítem con respecto a la escala, se incluyó en el análisis del coeficiente Alpha de Cronbach con la alternativa 'si se elimina el elemento'. Pudo observarse que en todos los casos se mantuvo el valor obtenido al principio, o uno parecido. Debido a estos resultados puede mantenerse la estructura obtenida (Tabla 10).

Tabla 10

Coeficientes Alpha de Cronbach con opción 'si se elimina el elemento' para cada dimensión

\begin{tabular}{|c|c|c|c|c|c|c|c|c|c|c|c|c|c|}
\hline \multicolumn{2}{|c|}{$\begin{array}{c}\text { Pasado } \\
\text { negativo }\end{array}$} & \multicolumn{2}{|c|}{$\begin{array}{c}\text { Pasado } \\
\text { positivo }\end{array}$} & \multicolumn{2}{|c|}{$\begin{array}{c}\text { Presente } \\
\text { fatalista }\end{array}$} & \multicolumn{2}{|c|}{$\begin{array}{c}\text { Futuro } \\
\text { positivo }\end{array}$} & \multicolumn{2}{|c|}{ Futuro neutro } & \multicolumn{2}{|c|}{$\begin{array}{c}\text { Presente } \\
\text { hedonista }\end{array}$} & \multicolumn{2}{|c|}{$\begin{array}{c}\text { Futuro } \\
\text { negativo }\end{array}$} \\
\hline Ítem & ? & Ítem & 圆 & Ítem & 国 & Ítem & ? & Ítem & ? & Ítem & 目 & Ítem & ? \\
\hline 13 & .79 & 2 & .71 & 17 & .73 & 11 & .60 & 5 & .73 & 31 & .77 & 6 & .74 \\
\hline 19 & .71 & 20 & .70 & 45 & .66 & 16 & .62 & 7 & .72 & 37 & .71 & 8 & .77 \\
\hline 30 & .71 & 23 & .69 & 46 & .69 & 32 & .60 & 24 & .75 & 38 & .75 & 56 & .74 \\
\hline 33 & .71 & 39 & .72 & 47 & .75 & 48 & .61 & 51 & .75 & 50 & .73 & & \\
\hline 41 & .70 & 43 & .70 & & & 54 & .61 & & & & & & \\
\hline 44 & .72 & & & & & 55 & .68 & & & & & & \\
\hline 59 & .71 & & & & & 62 & .69 & & & & & & \\
\hline 63 & .71 & & & & & & & & & & & & \\
\hline
\end{tabular}

En lo referido a determinar la estabilidad temporal de las puntuaciones se realizó una comparación pre - post test (o procedimiento de test / re-test), con prueba t para muestras relacionadas, en función de la cual se pudo establecer que no hubo diferencias estadísticamente significativas entre las administraciones, lo que se vio corroborado en las medias y desvíos de cada par (Tabla 11). Además, se realizaron análisis de correlación de Pearson, entre las versiones pre y post para cada dimensión, y se obtuvo para cada caso un $\mathrm{p}$ valor estadísticamente significativo, con coeficientes altos -mayores a .50 según lo sugerido por Cohen y Cohen (1983)- (Tabla 12). 
Revista ConCiencia EPG-Vol. 5- № 1 Enero - Junio 2020

ISSN: 2517-9896

https://doi.org/10.32654/CONCIENCIAEPG.5-1.5

Tabla 11

Prueba t de muestras relacionadas para estabilidad de las puntuaciones

\begin{tabular}{|c|c|c|c|c|c|c|}
\hline \multirow{2}{*}{ Reactivo } & \multicolumn{2}{|c|}{ Pre test } & \multicolumn{2}{|c|}{ Post test } & \multicolumn{2}{|c|}{ Valores Estadísticos } \\
\hline & Media & Desvío & Media & Desvío & $\bar{t}$ & $p$ \\
\hline Ítem2 & 4.09 & .781 & 3.94 & .968 & 1.406 & .169 \\
\hline Ítem5 & 3.14 & 1.061 & 3.17 & 1.098 & -.183 & .856 \\
\hline Ítem6 & 2.69 & 1.078 & 2.54 & .919 & 1.000 & .324 \\
\hline Ítem7 & 2.69 & 1.157 & 2.86 & 1.216 & -1.528 & .136 \\
\hline Ítem8 & 2.77 & .910 & 2.57 & .917 & 1.747 & .090 \\
\hline Ítem11 & 4.03 & .747 & 4.06 & .765 & -.226 & .822 \\
\hline Ítem13 & 3.69 & 1.051 & 3.57 & 1.145 & .941 & .353 \\
\hline Ítem16 & 3.91 & .981 & 3.63 & 1.114 & 1.617 & .115 \\
\hline Ítem17 & 2.09 & 1.067 & 1.97 & .891 & .612 & .545 \\
\hline Ítem19 & 2.60 & 1.006 & 2.54 & 1.172 & .329 & .744 \\
\hline Ítem20 & 4.00 & .767 & 3.57 & 1.008 & 3.112 & .054 \\
\hline Ítem23 & 3.43 & 1.195 & 3.40 & 1.241 & .115 & .909 \\
\hline Ítem24 & 3.94 & .838 & 3.63 & 1.114 & 1.724 & .094 \\
\hline Ítem30 & 2.51 & 1.040 & 2.54 & 1.010 & -.206 & .838 \\
\hline Ítem31 & 4.23 & .598 & 4.11 & .718 & .941 & .353 \\
\hline Ítem32 & 4.09 & .742 & 4.14 & .648 & -.495 & .624 \\
\hline Ítem33 & 2.86 & 1.033 & 2.60 & 1.090 & 2.491 & .058 \\
\hline Ítem37 & 3.23 & 1.031 & 3.31 & 1.231 & -.475 & .638 \\
\hline Ítem38 & 3.46 & 1.010 & 3.66 & 1.136 & -1.156 & .256 \\
\hline Ítem39 & 4.06 & .873 & 3.94 & .873 & .941 & .353 \\
\hline Ítem41 & 2.37 & 1.190 & 2.26 & 1.197 & .892 & .379 \\
\hline Ítem43 & 3.89 & .900 & 3.66 & 1.259 & 1.435 & .160 \\
\hline Ítem44 & 2.69 & 1.207 & 2.63 & 1.031 & .361 & .721 \\
\hline Ítem45 & 3.14 & 1.033 & 3.06 & 1.110 & .517 & .609 \\
\hline
\end{tabular}


Revista ConCiencia EPG-Vol. 5- № 1 Enero - Junio 2020

\begin{tabular}{lcccccc} 
Ítem46 & 2.37 & 1.140 & 2.14 & 1.004 & 1.541 & .133 \\
Ítem47 & 2.03 & 1.071 & 2.03 & 1.224 & .000 & .402 \\
Ítem48 & 3.66 & .873 & 3.77 & .843 & -.849 & .061 \\
Ítem50 & 2.83 & 1.098 & 3.26 & 1.197 & -2.674 & .539 \\
Ítem51 & 2.80 & 1.183 & 2.71 & 1.319 & .620 & .295 \\
Ítem54 & 3.54 & .919 & 3.71 & .926 & -1.063 & .324 \\
Ítem55 & 3.06 & .968 & 3.17 & .857 & -1.000 & .886 \\
Ítem56 & 1.119 & 2.40 & 1.143 & .144 & .128 \\
Ítem59 & 2.43 & 1.114 & 2.43 & .948 & 1.558 & .058 \\
Ítem62 & 2.63 & .981 & 2.37 & 1.165 & -1.966 & .998 \\
Ítem63 & 2.09 & 1.060 & 2.63 & .942 & .000 & \\
\hline
\end{tabular}

Tabla 12

Correlación de Pearson entre las dimensiones para versiones pre y post

\begin{tabular}{|c|c|c|}
\hline \multicolumn{3}{|c|}{ Estabilidad global del instrumento - Correlación entre test - retest } \\
\hline \multirow[t]{2}{*}{ Variables } & \multicolumn{2}{|c|}{ Correlación de Pearson } \\
\hline & $r$ & $\boldsymbol{P}$ \\
\hline $\begin{array}{l}\text { Pasado negativo } \\
\text { (pre - post) }\end{array}$ & .876 & .000 \\
\hline $\begin{array}{l}\text { Pasado positivo } \\
\text { (pre - post) }\end{array}$ & .791 & .000 \\
\hline $\begin{array}{l}\text { Presente fatalista } \\
\text { (pre - post) }\end{array}$ & .716 & .000 \\
\hline $\begin{array}{l}\text { Futuro positivo } \\
\text { (pre - post) }\end{array}$ & .668 & .000 \\
\hline $\begin{array}{l}\text { Futuro neutro } \\
\text { (pre - post) }\end{array}$ & .852 & .000 \\
\hline $\begin{array}{l}\text { Presente hedonista } \\
\quad \text { (pre - post) }\end{array}$ & .753 & .000 \\
\hline $\begin{array}{l}\text { Futuro negativo } \\
\text { (pre - post) }\end{array}$ & 692 & .000 \\
\hline
\end{tabular}


Por último, se realizaron los cruces entre las dimensiones correspondientes a perspectiva temporal con personalidad (Tabla 13), para analizar, por medio de correlaciones de Pearson, la validez criterio. De esta manera, puede observarse que los resultados se dieron de acuerdo a lo planteado por la teoría, es decir que las asociaciones fueron positivas cada vez que las dimensiones de carácter positivo de la perspectiva temporal se cruzaban con dimensiones de sentido positivo de la personalidad, y lo propio sucedió con las de sentido negativo.

Para este cruce de variables, las asociaciones observadas fueron entre:

I. Pasado negativo y dos de las dimensiones de personalidad: Extraversión y Agradabilidad. En ambos casos se trata de asociaciones negativas (o indirectas) y débiles.

II. Pasado positivo y cuatro dimensiones de personalidad: Neuroticismo, Extraversión, Apertura a la experiencia y Responsabilidad. En todos los casos se trata de asociaciones débiles, negativa (o indirecta) respecto del Neuroticismo y positivas (o directas) para el resto.

III. Futuro positivo y las cinco dimensiones de personalidad: Neuroticismo, Extraversión, Apertura a la experiencia, Agradabilidad y Responsabilidad. En este caso todas fueron también débiles, indirecta para Neuroticismo $\mathrm{y}$ directas las restantes.

IV. Futuro neutro y una dimensión de personalidad: Neuroticismo; se trata de una asociación positiva (o directa) y débil.

V. Presente hedonista y cuatro de las dimensiones de personalidad: Neuroticismo, Extraversión, Apertura a la experiencia y Responsabilidad. Son asociaciones débiles y negativa (o indirecta) para Neuroticismo y directas para el resto.

VI. Presente fatalista y dos dimensiones de personalidad: Neuroticismo y Agradabilidad. En ambos casos, son asociaciones débiles, positiva para Neuroticismo y negativa (o inversa) para Agradabilidad.

\section{Tabla 13}

Asociaciones entre Perspectiva temporal y Personalidad

\begin{tabular}{lrrrrrrrr}
\hline & $\begin{array}{l}\text { Pasado } \\
\text { negativo }\end{array}$ & $\begin{array}{l}\text { Pasado } \\
\text { positivo }\end{array}$ & $\begin{array}{l}\text { Futuro } \\
\text { negativo }\end{array}$ & $\begin{array}{l}\text { Futuro } \\
\text { positivo }\end{array}$ & $\begin{array}{l}\text { Futuro } \\
\text { neutro }\end{array}$ & $\begin{array}{l}\text { Presente } \\
\text { hedonista }\end{array}$ & $\begin{array}{l}\text { Presente } \\
\text { fatalista }\end{array}$ \\
\hline \multirow{2}{*}{ Neuroticismo } & $\mathrm{r}$ & -.037 & .164 & -070 & .322 & .138 & .113 & -.108 \\
& $\mathrm{p}$ & .502 & .003 & .202 & .000 & .012 & .040 & .049 \\
\hline Extraversión & $\mathrm{r}$ & .180 & .114 & .014 & .161 & .092 & .122 & -.049 \\
\hline
\end{tabular}




\begin{tabular}{|c|c|c|c|c|c|c|c|c|}
\hline & $p$ & .001 & .038 & .806 & .003 & .093 & .026 & .376 \\
\hline \multirow{2}{*}{$\begin{array}{l}\text { Apertura a la } \\
\text { experiencia }\end{array}$} & $r$ & .041 & .202 & -.067 & .189 & .029 & .127 & -.025 \\
\hline & $P$ & .454 & .000 & .225 & .001 & .598 & .021 & .649 \\
\hline Agradabilidad & $p$ & .000 & .255 & .098 & .002 & .064 & .537 & .002 \\
\hline Responsabilidad & $r$ & -.047 & .113 & -.087 & .258 & .091 & .170 & -.042 \\
\hline
\end{tabular}

\section{Discusión}

En función de los análisis realizados para la validación de este inventario puede decirse que el resultado es un instrumento que da cuenta de una adecuada calidad, y por tanto estructura, ya que el mismo responde a las exigencias esperadas.

La solución final brinda la integración de 35 ítems, distribuidos en siete factores: 1- Pasado negativo (PN), 2Pasado positivo (PP), 3- Presente fatalista (PF), 4- Futuro positivo (FP), 5- Futuro neutro (FNe), 6- Presente hedonista (PH) y 7- Futuro negativo (FN). Esto fue trabajado, en primera instancia, a partir del juicio experto y luego corroborado mediante análisis factorial exploratorio, por medio de rotación ortogonal Varimax, obteniendo de la misma un alto índice de esfericidad, al igual que los valores de las correlaciones anti-imagen y la extracción de la comunalidades. Una vez obtenida la dimensionalidad se profundizaron los análisis de discriminación de ítems, consistencia interna y estabilidad de la técnica, y se realizaron análisis para la validez de criterio.

En términos generales, puede decirse que el inventario difiere del original, así como de la mayoría de las validaciones que lleva hasta el momento en lo referido a la cantidad de ítems y dimensiones (e.g. Apostolidis \& Fieulaine, 2004; Díaz Morales, 2006; Leite \& Pascuali, 2008; Oyanadel, Buela Casal \& Pérez Fortis, 2014; Sircova et al., 2014). No obstante, esto fue planteado en estos términos, ya que se esperaba incorporar otras alternativas, partiendo de lo esbozado teóricamente que sostiene la percepción temporal como rasgo cognitivo, y entender que, si el constructo se plantea en estos términos, también exige la necesidad de ampliar las posibilidades propuestas respecto a la vivencia subjetiva del mismo, para que contemple la mayor cantidad de vivencias posibles. Para esto se tuvieron en cuenta los resultados de otras validaciones, que contemplaban otras dimensiones, como son 
los casos de Suecia, en la cual se tuvo en cuenta el futuro negativo (Carelli, Wiberg \& Wiberg, 2011), y en la República Checa, quienes consideraron el futuro positivo (Kostal et al., 2015).

Siguiendo esta idea, en lo que refiere a los aspectos éticos y émicos se realizó la triple traducción del inventario original, llegando a un acuerdo respecto de los significados de la consigna y de los ítems; luego se presentó la versión traducida a 30 voluntarios, que participaron de la prueba piloto, para ajustar aspectos idiomáticos contextuales. Además, un grupo de 5 jueces expertos mostraron acuerdo respecto de la distribución de los ítems en las dimensiones planteadas, y todo esto aportó validez de contenido. En lo referido a la validez de constructo, el análisis factorial exploratorio (realizado con rotación ortogonal Varimax) dio cuenta de la estructura antes mencionada, que, tal como fue mencionado antes, difiere de la estructura original, no obstante, era lo que se esperaba. Una vez verificada la estructura de la nueva versión, se analizó la evidencia de confiabilidad, y los resultados mostraron valores adecuados tanto para la estabilidad temporal como para la consistencia interna.

La posibilidad de adicionar nuevas dimensiones fue considerada no solo porque ya habían sido tenidas en cuenta en otras versiones, sino porque la teoría entiende a la perspectiva temporal como rasgo cognitivo estable, que involucra aspectos actitudinales y comportamentales (Boniwell, 2009; Thiébaut, 1998; Vázquez et al., 2016, Webster, 2011), y no solo como el momento en el cual un individuo se ubique. Además, dado que se trata de un mecanismo psicológico, permite a los seres humanos adaptarse, siguiendo un desarrollo funcional. Teniendo en cuenta esto, se entiende que ampliar las posibilidades de identificación temporal es ampliar las posibilidades de asociación con otras variables, y todo lo que ello pudiera involucrar, ya que la perspectiva temporal no implica solo que un sujeto se ubique en determinada disposición temporal, eso sería caer en un reduccionismo dado que es solo una parte de su función, sino que debe tenerse en cuenta que todas las actividades de las personas se encuentran reguladas temporalmente, y este acto conlleva una reflexión y su respectiva valoración (Crespi, 2010; Crespi \& Mikulic, 2011; Nurmi, 1991). De esta manera, ampliar las posibilidades de su análisis permite tener en cuenta una dinámica más minuciosa del individuo y sus diferentes procesos. En este punto, se tiene en cuenta lo planteado por Nurmi (1991) cuando establece que se trata de un proceso complejo, a un nivel que también involucra aspectos biológicos, y que se encuentra asociado a las expectativas que las personas tienen de sí mismas en el futuro y a las reflexiones que se realizan a partir de ello; todo esto condicionado por el ámbito cultural y social de cada sujeto y su etapa evolutiva. No obstante, si bien la vivencia subjetiva no permite establecer lapsos específicos para cada actividad y eso después generalizarse, resulta importante desarrollar herramientas que permitan describir cada vivencia de una manera minuciosa, y que permita realizar análisis e interpretaciones más específicas. En ese sentido, se cuenta con un instrumento que amplía dicha 
posibilidad de análisis, dado que especifica con más detalle la orientación temporal, lo que a su vez puede proporcionar un análisis más minucioso de otros aspectos asociados. Además, se refuerza el desarrollo teórico, dado que se trata de un constructo que aún no está unificado respecto de su entendimiento, y la evidencia permite apoyar la idea de la perspectiva temporal como un aspecto cognitivo que permite elaborar planes y proyectos, y que puede convertirse en una característica estable de la personalidad, siendo integrado en cada etapa al espacio vital del sujeto (Gjesme, 1981; Husman \& Lens, 1999).

\section{Limitaciones}

La sugerencia principal es realizar análisis factorial confirmatorio. Aunque se han realizado variados procedimientos para dar cuenta de la calidad general de la

\section{Referencias}

Anagnostopoulos, F. \& Griva, F. (2012). Exploring time perspective in Greek young adults: Validation of the Zimbardo Time Perspective Inventory and relationships with mental health indicators. Social Indicators Research, 106, 41-59. https://dx.doi.org/10.1007/s11205011-9792-y.

Apostolidis, T. \& Fieulaine, N. (2004). Validation française de l'échelle de temporalité [French validation of the time perspective inventory]. Revue Européenne de Psychologie Appliquée, 54, 207-217. escala, y los resultados fueron buenos, ampliar y corroborar estos resultados resulta óptimo. Además, podría ampliarse lo referido a la validez de criterio, dado que en este estudio se ha realizado tomando como referencia la Personalidad, según la teoría de los cinco grandes, pero la literatura sugiere la asociación de la Perspectiva temporal a variables como Motivación, Morosidad académica, Toma de decisiones, Desempeño académico (Difabio de Anglat et al., 2018; Fernández \& Macbeth, 2017,2018; González Lomelí et al., 2006; Gutiérrez Braojos et al., 2014; Herrera et al., 2015; Lens \& Herrera, 2005; Simons et al., 2001). En ese sentido, podrían realizarse estudios que amplíen los ya existentes con respecto a este constructo, pero con esta nueva estructura factorial, además de una nueva validación en población general de adultos, y determinar si se mantienen las características.

Bleger, J. (1963). Psicología de la conducta. Paidós.

Boniwell, I. (2009). Perspectives on time. En C.R. Snyder \& S.J. Lopez (Eds.), The Oxford Handbook of Positive Psychology (2da. ed., pp. 295-302). New York: Oxford University Press.

Boniwell, I. \& Zimbardo, P. (2004). Balancing one's time perspective in pursuit of optimal functioning. En P.A. Linley \& S. Joseph (Eds.), Positive psychology in practice (Cap. X, pp. 165178). Hoboken, NJ: Wiley. 
Boyd, J. N. \& Zimbardo, P. G. (2005). Time perspective, health, and risk taking. En A. Strahman \& J. Joireman (Eds.). Understanding behavior in the context of time: Theory, research and applications (pp. 85-107). Mahwah, NJ: Erlbaum.

Brenlla, M.E., Willis, B. \& Germano, G. (2017). Estimación del tiempo y perspectiva temporal en etapas de la adultez. Investigaciones en Psicología, 21(1), 27-34.

Carelli, M. G., Wiberg, B., \& Wiberg, M. (2011). Development and construct validation of the Swedish Zimbardo Time Perspective Inventory. European Journal of Psychological Assessment, 27, 220-227.

Castro-Solano, A. \& Casullo, M.M. (2001). Rasgos de personalidad, bienestar psicológico y rendimiento académico en adolescentes argentinos. Interdisciplinaria, 18(1), 65-85.

Cohen, J. (1988). Statistical Power Analysis for the Behavioral Sciences. Second Edition. Hillsdate, NJ: LEA.

Cohen, J. (1992). Fuzzy Methodology. Psychological Bulletin, 112(3), 409410.

Corral-Verdugo, V., Fraijo Sing, B. \& Pinheiro, J. Q. (2006). Sustainable behavior and time perspective: Present, past, and future orientations and their relationship with water conservation behavior. Interamerican Journal of Psychology, 40,139- 147.
Crespi, M. (2010). Estudio de la perspectiva temporal futura en una muestra de liberados condicionales. II Congreso Internacional de Investigación $y$ Práctica Profesional en Psicología XVII. Jornadas de Investigación Sexto Encuentro de Investigadores en Psicología del MERCOSUR. Facultad de Psicología - Universidad de Buenos Aires, Buenos Aires.

Crespi, M. \& Mikulic, I. M. (2011) Reinserción social: estudio de la perspectiva temporal futura en sujetos que han recobrado su libertad. Anuario de Investigaciones, 18(1), 401-408.

D’Alessio, M., Guarino, A., De Pascalis, V. \& Zimbardo, P. G. (2003). Testing Zimbardo's Stanford Time Perspective Inventory (STPI) - Short Form. An Italian study. Time \& Society, 12(2/3), 333-347.

Díaz-Morales, J. F. (2006-a). Estructura factorial y fiabilidad del Inventario de perspectiva Temporal de Zimbardo. Psicothema, 18(3), 565-571.

Díaz Morales, J.F. (2006-b). Perspectiva temporal futra y ciclo vital. Anales de Psicología, 22(1), 52-59.

Difabio de Anglat, H., Vázquez, S.M. \& Noriega Biggio, M. (2018). Orientación temporal y metas vitales en estudiantes argentinos. Revista de Psicología, 36(2), 661-700. https://dx.doi.org/10.18800/psico.20 1802.010

Fernández Lamarra, N. (2009). La educación superior en América Latina. 
Interrogantes y desafíos para el debate. Sociedad y Discurso, 21, 94-113.

Fernández, H. \& Macbeth, G. (2017). Riesgo $\mathrm{y}$ arrepentimiento en la toma de decisiones: rol de la perspectiva de tiempo futuro y el contenido de la meta. Revista de Psicología, 13(26), 6576.

Fernández, H. \& Macbeth, G. (2018). Perspectiva de tiempo futuro, metas y sub-metas: su rol en la toma de decisiones. Latin American Journal of Psychological Science, 10(2). https://dx.doi.org/10.5872/psiencia/ 10.2.23

Fraisse, P. (1963). The psychology of time. Westport: Greenwood.

Galarraga, M. L. (2016). Perspectiva temporal futura, apoyo social $y$ afrontamiento al estrés en alumnos de escuelas secundarias de la Provincia de Buenos Aires (Tesis de Maestría en Psicodiagnóstico y Evaluación Psicológica). Universidad de Buenos Aires, Buenos Aires.

García de Fanelli, A.M. (2014). Rendimiento académico y abandono universitario: modelos, resultados y alcances de la producción académica en la Argentina. Revista Argentina de Educación Superior, 6(8), 9-38.

Gjesme, T. (1981). Is there any future in achievement motivation? Motivation and Emotion, 2, 115-138.

Goldenhersch, H., Coria, A. \& Saino, M. (2011). Deserción estudiantil: desafíos de la universidad pública en un horizonte de inclusión. Revista Argentina de Educación Superior, 3(3), 96-120-

González Lomelí, D., Maytorena, M.A., Lohr Escalante, F. \& Carreño Cruz, E.A. (2006). Influencia de la perspectiva temporal y la morosidad académica en estudiantes universitarios. Revista Colombiana de Psicología, (15), 15-24.

Gutiérrez Braojos, C., Salmerón Pérez, H. \& Muñoz Cantero, J.M. (2014). El efecto modulador de los patrones temporales sobre el logro en el aprendizaje autorregulado. Revista de Psicodidáctica, 19(2), 267-287. Doi: 10.1387/RevPsicodidact.10066

Hair, J. F., Anderson, R. E., Tatham, R. L., \& Black, W. C. (1999). Análisis multivariante. Madrid: Prentice Hall.

Herrera, D., Matos, L., Martínez, P. \& Lens, W. (2015). Perspectiva de tiempo futuro y satisfacción con la vida en adolescentes: un estudio transcultural (Dedicado al Prof. Dr. Willy Lens). Revista de Orientación Educacional, 29(55), 37-54

Husman, J. \& Lens, W. (1999). The Role of the Future in Student Motivation. Educational Psychologist, 34, 113-125.

Keough, K.A., Zimbardo, P.G. \& Boyd, J.N. (1999). Who's smoking, drinking and using drugs? Time perspective as a predictor of substance use. Basic and Applied Social Psychology, 21(2), 149164

Kostal, J., Klicperová-Baker, M., Lukavská, K. \& Lukavsky, J. (2015). Short version of 
the Zimbardo Time Perspective Inventory (ZTPI-short) with and without the Future-Negative scale, verified on nationally, representative samples. Time \& Society, o(0) 1-24.

Leite, U. R., \& Pasquali, L. (2008). Estudo de validação do Inventário de Perspectiva de Tempo do Zimbardo [Zimbardo time perspective inventory validation study]. Avaliação Psicológica, 7, 301320.

Lens, W. (1998). El rol de la perspectiva de tiempo futuro en la motivación estudiantil. Persona, 1, 67-94.

Lens, W. \& Herrera, D. (2005). Perspectiva de tiempo futuro, valores, instrumentalidad percibida. Autoconcepto en adolescentes de colegios y universidades públicas y privadas en Lima. Revista de Psicología, 1(1), 120148.

Lersch, P.H. (1966). Aufbau der person. Munchen: Johann Ambrosius Barth.

Lewin, K. (1942). Time perspective and morale. En G. Watson (eds.), Civilian morale. Boston Houghton Mifflin.

Liniauskaite, A. \& Kairys, A. (2009). The Lithuanian version of the Zimbardo time perspective inventory. Psichologija, 40, 66-87.

Martínez Arias, M. R. (1999). El análisis multivariante en la investigación científica. Madrid: La Muralla.

Milfont, T. L., Andrade, P. R., Belo, R. P. \& Pessoa, V. S. (2008). Testing Zimbardo time perspective inventory in a
Brazilian sample. Interamerican Journal of Psycohology, 42, 49-58.

Nurmi, J.E. (1991). How do adolescents see their future? A review of the development of future orientation and planning. Developmental Review, 11(1) 1-59.

Nuttin, J. (1964). The future time perspective in human motivation and learning. In proceedings of the 17th international Congress of Psychology (pp. 60-82). Amsterdam: NorthHolland.

Nuttin, J. (1985). Future time perspective and Motivation. Louvain: Leuven University Press y Lawrence Erlbaum Associates.

Orkibi, H. (2014). Psychometric Properties of the Short Version of the Zimbardo Time Perspective Inventory. Evaluation \& the Health Professions, 1 27. doi: $10.1177 / 0163278714531601$

Ortuño, V. \& Gamboa, V. (2009). Estrutura factorial do Zimbardo Time Perspective Inventory-ZTPI numa amostra de estudantes universitarios portugueses [Factorial structure of Zimbardo Time Perspective InventoryZTPI in a simple of Portuguese university students]. Avances en Psicología Latinoamericana, 27, 21-32.

Oyandel, C., Buela Casal, G. \& Pérez- Fortis, A.

(2014).

PropiedadesPsicométricasdelInventar io de Orientación Temporal de Zimbardo en una muestra chilena. Terapia Psicológica, 32(1), 47-55. 
Seema, R. \& Sircova, A. (2013). Mindfulnessa time perspective? Estonian study. Baltic Journal of Psychology, 14, 1-2.

Shimojima, Y., Sato, K. \& Ochi, K. (2012). Factor structure of the Japanese version of the Zimbardo Time Perspective Inventory (ZTPI). The Japanese Journal of Personality, 21, 7483. doi: 10.2132/personality.21.74

Simons, J., Dewitte, S. \& Lens, W. (2001). Efectos de tipo de instrumentalidad sobre variables motivacionales $\mathrm{y}$ cognitivas. Persona, 4, 161-178.

Sircova, A., van de Vijver, F.J.R., Osin, E., Milfont, T.L., Fieulaine, N., Kislali Erginbilgic, A. \& Zimbardo, P.G. (2014). A global look at time: a 24-country study of the equivalence of the Zimbardo Time Perspective Inventory. SAGE Open, 4(1), 1-12. Doi: $10.1177 / 2158244013515686$

Sircova, A., van de Vijver, F.J.R., Osin, E., Milfont, T.L., Fieulaine, N., Kislali Erginbilgic, A. \& Zimbardo, P. G. (2015). Time Perspective profiles of cultures. En M. Stolarski, N. Fieulaine \& W. van Beek (Eds.), Time Perspective Theory; Review, Research and Application. Switzerland: SPRINGER. Doi: 10.1007/978-3-319-07368-2

Soria, F. H., \& Dalfaro, N.A. (2012). El desgranamiento en la carrera de ingeniería química de la UTN. Memorias de las II Jornadas de Investigación en ingeniería del NEA y Países Limítrofes. Universidad Tecnológica Nacional. Facultad Nacional Resistencia
Stolarski, M., Matthews, G., Postek, S., Zimbardo, P.G. \& Bitner, J. (2013). How we feel is a matter of time: relationships between Time Perspectives and mood. Journal of Happiness Studies. Doi: 10.1007/s10902-013-9450-y

Tabachnick, B. y Fidell, L. (2001). Using multivariate statistics. New York: Harper \& Row.

Vázquez, E. M., Difabio de Anglat, H. E. \& Noriega Biggio, M. (2016). Perspectiva temporal y estilos de personalidad en estudiantes argentinos. Interdisciplinaria, 33(2).

Zaleski, Z. (1994). Towards a psychology of the personal future. En Z. Zaleski (Ed.), Psychology of future orientation. Lublin, Polonia: Towarzystwo Naukowe KUL.

Zimbardo, P., Keough, K. \& Boyd, J.N. (1997). Present time perspective as a predictor of risky driving. Personality and Individual Differences, 23(6), 1007 1023. Doi:10.1016/S0 19 18869(97)00113-X

Zimbardo, P.G. \& Boyd, J.N. (1999). Putting time in perspective: a valid reliable individual-differences metric. Journal of Personality and Social Psychology, 77(6), 1271-1288.

Zimbardo, P. (2002). Just think about it: Time to take our time. Psychology Today, 35, 62. 